\title{
BRINQUEDO SEM BRINCADEIRA: REFLEXÕES SOBRE A INDÚSTRIA DO BRINCAR NA INFÂNCIA CONTEMPORÂNEA
}

\author{
JUGUETE SIN JUEGO: REFLEXIONES SOBRE LA INDUSTRIA JUGADORA EN LA \\ INFANCIA CONTEMPORÁNEA
}

\author{
TOY WITHOUT PLAY: REFLECTIONS ON THE PLAYING INDUSTRY IN \\ CONTEMPORARY CHILDHOOD
}

\author{
Marta Regina Furlan de OLIVEIRA ${ }^{1}$ \\ Ravelli Henrique de SOUZA ${ }^{2}$ \\ Karina de Toledo ARAÚJO ${ }^{3}$
}

RESUMO: Esse artigo objetiva refletir sobre a indústria do brincar na infância contemporânea e, especificamente, analisar sobre o brinquedo tecnológico enquanto materialização lúdica pelo viés do consumo. Ainda, pensar sobre o brinquedo e a expropriação do brincar enquanto necessidade humana e lúdica da criança. Os brinquedos industrializados retiram da criança o prazer da descoberta, criatividade, imaginação, coletividade e ludicidade. Esse ensaio é fruto dos estudos realizados no GEPEITC - Grupo de Estudos e Pesquisas em Educação, Infância e Teoria Crítica na Universidade Estadual de Londrina. A metodologia é um estudo bibliográfico em Max Horkheimer e Theodor Adorno no que se refere à Indústria Cultural e das reflexões de Walter Benjamim sobre o brincar na sociedade contemporânea. Como resultado, o brincar e a brincadeira da criança contemporânea precisam ser ressignificados para além do objeto - brinquedo, em prol da experiência do brincar enquanto necessidade humana e possibilidade de interação criança mundo; criança - outro.

PALAVRAS-CHAVE: Infância. Brincar tecnológico. Indústria cultural. Contemporaneidade.

RESUMEN: Este artículo tiene como objetivo reflexionar sobre la industria del juego en la infancia contemporánea $y$, específicamente, analizar el juguete tecnológico como una materialización lúdica por sesgo de consumo. Además, tiene como objetivo pensar en el juguete y la expropiación del juego como una necesidad humana y lúdica del niño. Los juguetes industrializados quitan de los niños el placer del descubrimiento, la creatividad, la imaginación, la colectividad y la diversión. Este ensayo es el resultado de estudios realizados en GEPEITC - Grupo de Estudios e Investigación en Educación, Infancia y Teoría Crítica de la Universidad Estatal de Londrina. La metodología es un estudio bibliográfico de Max

\footnotetext{
${ }^{1}$ Universidade Estadual de Londrina (UEL), Londrina - PR - Brasil. Docente do programa de pós-graduação em Educação. Pós-doutorado em Educação. ORCID: http://orcid.org/0000-0003-2146-2557. E-mail: marta.furlan@yahoo.com.br

${ }^{2}$ Universidade Estadual de Londrina (UEL), Londrina - PR - Brasil. Mestrando bolsista Capes/CNPQ do programa de pós-graduação em Educação. ORCID: http://orcid.org/0000-0001-9441-1684. E-mail: ravelli_28@hotmail.com

${ }^{3}$ Universidade Estadual de Londrina (UEL), Londrina - PR - Brasil. Docente do curso de Licenciatura em Educação Física, Departamento Estudos do Movimento Humano (UEL). E-mail: karina.araujo@uel.br
} 
Horkheimer y Theodor Adorno sobre la industria cultural y las reflexiones de Walter Benjamín sobre el juego en la sociedad contemporánea. Como resultado, el juego y el juego del niño contemporáneo deben ser resignificados más allá del objeto de juguete, a favor de la experiencia del juego como una necesidad humana y la posibilidad de interacción niño mundo, niño - otro.

PALABRAS CLAVE: Infancia. Juego tecnologico. Industria cultural. Contemporaneidad.

ABSTRACT: This article aims to reflect on the play industry in contemporary childhood and, specifically, to analyze the technological toy as a playful materialization by consumption bias. Also, it aims to think about the toy and the expropriation of play as a human and playful need of the child. Industrialized toys take away from children the pleasure of discovery, creativity, imagination, collectivity and playfulness. This essay is the result of studies conducted at GEPEITC - Group of Studies and Research in Education, Childhood and Critical Theory at the State University of Londrina. The methodology is a bibliographical study by Max Horkheimer and Theodor Adorno regarding the Cultural Industry and Walter Benjamin's reflections on playing in contemporary society. As a result, playing and the contemporary child's play need to be re-signified beyond the toy object, in favor of the experience of play as a human need and the possibility of interaction child - world, child-other.

KEYWORDS: Childhood. Technological play. Cultural industry. Contemporaneity.

\section{Introdução}

[...] todas as manifestações da vida infantil não pretendem outra coisa senão conservar em si sentimentos essenciais (BENJAMIN, 1984).

As crianças contemporâneas têm suas infâncias marcadas pela indústria do brincar mediada pelo brinquedo tecnológico que, de certa forma, distancia a criança da experiência lúdica enquanto relação criança - mundo; criança - outro, tornando-a, desde o berço em mera consumidora do objeto-brinquedo.

O entretenimento, a brincadeira, a imaginação e a fantasia são condicionados ao processo de persuasão, manipulação e sedução da mercadoria, tendo como porta-voz a Indústria Cultural que estimula os indivíduos (crianças e adultos) ao processo consumista da mercadoria do brinquedo tecnológico. A tecnologia materializada no brinquedo retira da criança a possibilidade de exercitar o pensamento e a criação para manusear um brinquedo e, compromete a autonomia social. Ainda, promove a sedução em massa de adultos e crianças para o mundo ideológico do 'ter' em detrimento do 'ser', uma vez que tanto adultos quanto crianças são envolvidos por uma lógica em que tudo tem preço e objetivo de mercado em sintonia com a padronização do gosto, pensamentos e ações. 
Consequentemente, as crianças têm suas infâncias marcadas por esse modelo de produção cultural e ideológica da mercadoria via indústria do brincar e consumo. A fantasia animada e romantizada e a diversão pela experiência do brincar parecem se confundir com a própria realidade da mercadoria e do produto - brinquedo, em que a propaganda e a cultura midiática promovem a atenção das crianças e, burilam seu mundo simbólico para a aquisição do objeto lúdico em detrimento da experiência do brincar enquanto necessidade do sujeito brincante.

Diante disso, esse ensaio tem como objetivo principal refletir sobre a indústria do brincar na infância contemporânea e, especificamente, analisar sobre o brinquedo tecnológico enquanto materialização lúdica pelo viés do consumo. Ainda, pensar sobre o brinquedo e a expropriação do brincar enquanto necessidade humana e lúdica da criança.

Esse ensaio é fruto dos estudos realizados no GEPEITC - Grupo de Estudos e Pesquisas em Educação, Infância e Teoria Crítica na Universidade Estadual de Londrina. A metodologia é um estudo bibliográfico em Max Horkheimer e Theodor Adorno no que se refere à Indústria Cultural e das reflexões de Walter Benjamim sobre o brincar na sociedade contemporânea.

\section{Infância do brincar tecnológico: do berço ao consumo}

Você veio ao mundo porque foi escolhida pela Estrela para brincar com a nova linha de Bonecas X. Você existe para comer potes e potes de Danoninho. O funcionamento de todas as coisas é simples - você pede, a mamãe compra; você aperta o botão, o brinquedo se mexe (KEHL, 1991, p. $63)$.

A partir da afirmativa de Kehl (1991) partimos do pressuposto que conforme muda a sociedade, as concepções de educação e ser humano sofrem alterações, sendo que, a forma de ver e conceituar a infância e a criança também modificam. À luz da compreensão da infância enquanto condição biológica, história, social revelamos que esta não está limitada a um lugar cronológico, nem algo como uma idade ou um estado psicossomático do desenvolvimento. Sua condição de infância é, de maneira mais complexa, uma tentativa de pensar a humanidade enquanto experiência de ser e estar no mundo.

Nesse sentido, ao pensar no contexto atual marcado pela lógica da Indústria Cultural e do consumo de mercadoria, a infância e a criança são percebidas à luz desta égide social e 
econômica, bem como suas formas de brincar e interagir no mundo. Nesse cenário, os brinquedos industrializados e ou tecnológicos são referências marcantes na vida infantil, além de outros acessórios, como roupas de marcas, enlatados, etc, alterando também os tipos de objetos lúdicos e infantis e o próprio conceito de brincar. Essa mudança se dá, principalmente, com as alterações do mundo do trabalho, em que a sociedade tem que se adaptar à nova realidade do mercado e da produção, modificando-se em cada contexto histórico e econômico.

Para Belloni (2009, p. 72-73), todos e, especificamente, as crianças constituem em um grupo demarcado pela sua crescente importância como atores no mercado de consumo: "as crianças são alvo de poderosos holofotes de influências múltiplas e contraditórias. Estão expostas as mensagens, imagens e sons cujo poder comunicacional é forte e, muitas vezes chocante, sobre temas que elas nem sempre compreendem [...]". Pelo entendimento da especificidade da criança, o brinquedo tem um lugar de destaque.

A mercadoria, portanto, se realiza como brinquedo, como outro produto qualquer, buscando satisfazer outras necessidades que o homem vai criando e recriando sob a forma de outros produtos. Marx (1985, p. 44) afirma que "as propriedades materiais só interessam pela utilidade que dão às mercadorias, por fazerem destas valores-de-uso. Nem um valor-de-uso vale tanto quanto outro, quando está presente na proporção adequada [...]”. Nesta lógica, a mercadoria não está subordinada ao brinquedo mercadoria. Constitui-se, todavia, como brinquedo, criando um sujeito determinado para realizá-la pelo processo fetichizante do produto que 'toma' o brincar enquanto lugar da necessidade lúdica do sujeito em detrimento do brinquedo que passa ser o condutor do brincar.

Nesse sentido, mercadorias decidem o comportamento dos homens e crianças, uma vez que Marcuse (1975, p. 26) afirma que as individualidades "são mercadorias monopolizadas e socialmente condicionadas, que se fazem passar por algo natural" e, a ponto da criança que não tem o brinquedo ser 'anormal' ou desadaptada ao que já foi naturalizado pelo consumo. Como exemplo, a boneca Barbie que está na vida de uma parcela significativa da população infantil, seja ela de nível econômico melhor ou não.

Além disso, a indústria do brincar promove a generificação dos brinquedos para atender as representações privilegiadas da infância de meninos e meninas. $\mathrm{O}$ universo do brinquedo feminino privilegia, conforme a classe social e econômica dos grupos envolvidos, o espaço familiar da casa, a independência da mulher e sua inserção no mundo do trabalho, envolvendo, ao mesmo tempo, os laços afetivos, a doçura e a fragilidade. Já o universo do brinquedo masculino privilegia a força, o poder, a autoridade, a manipulação, as conquistas terrenas diversas, sucesso empresarial. 
$\mathrm{O}$ mercado parece apreender este corte que remete o brinquedo à criança. Toma-a como sujeito que brinca e produz objetos de brincar. Sobrepõe a esta condição aquela que interessa ao mercado: a necessidade e o poder para comprar. Recria, pois, necessidades de brincar pelo fortalecimento que dá à relação criança-comprar (brinquedo), criança-brincar. Nesse propósito, constrói o consumidor e o proprietário (do brinquedo) ao lado do ser que brinca e que, porque brinca, é alegre, feliz, segundo o discurso do mercado. ${ }^{4}$

$\mathrm{Na}$ tentativa de melhor esboçar essa análise acerca da indústria do brincar, chamamos atenção para a tradicional indústria de bonecas. Atualmente, nascem bonecas que se alteram conforme o tempo social e histórico. A boneca se relaciona a um sistema de produção que podemos chamar de industrial, mesmo que esta indústria tenha conservado, mais do que outras, aspectos artesanais. A boneca, nesse sentido, é o espelho da sociedade, refletindo conforme as concepções e critérios de cada época histórica.

Ao pensar na boneca industrializada contemporânea vemos predominar a boneca Barbie, que atua enquanto mulher, desejada, sedutora e extremamente vaidosa em um mundo de brilho, glamour, cores e acessórios. A boneca é representação do que a criança quer ser quando adulta, sendo fortemente marcada pela linguagem estabelecida durante o brincar com a Barbie, em que tudo gira em torno de uma vida de sucesso profissional, realização pessoal e afetiva, além de muita segurança e confiabilidade nas próprias ações enquanto mulher.

Linn (2006) reforça a mesma ideia ao anunciar campanhas de marketing feitas a partir de produtos licenciados (Barbie, Super-Heróis, Harry Potter), que enviam uma mensagem para as crianças, anunciando que qualquer coisa que produzam não é tão boa quanto aquela produzida pela indústria do brincar. Embutida em qualquer campanha de marketing está a mensagem de que os consumidores precisam daquele produto anunciado: as crianças que "precisam" dos brinquedos e acessórios de Barbie e Super-Heróis não podem imaginar-se brincando sem uma fantasia comprada ou uma roupa glamorosa de Barbie, por exemplo.

\footnotetext{
A boneca passa a significar a criança, seu ambiente e a própria infância, enquanto imagem manipulável, não do ser humano em geral, mas dele próprio enquanto criança. [...] Além das formas puramente infantis, trata-se de um mundo para e pela criança, que só existe em função das representações e desejos atribuídos à criança. É o traço da interpretação que os adultos fazem do imaginário e das aspirações das crianças (BROUGÈRE, 1995, p. 37).
}

${ }^{4}$ É interessante comentar que essa ideia é veementemente aceita em programas de comerciais em TV, em que as campanhas comemorativas ao Dia da Criança anunciam: A criança que não brinca logo fica séria e triste. A criança tem que brincar, dar gargalhadas, mergulhar na fantasia, ter brinquedos da Estrela... (BELLONI, 2009). 
As indústrias usam de todos os artifícios para seduzir cada vez mais crianças para o mundo lúdico industrializado. Não somente as indústrias de brinquedos estão interessadas neste alvo de consumo, mas também as de alimentos (balas, chicletes, chocolates, iogurtes), roupas, calçados, entre outros. Assim, o mercado trabalha para a criança (alvo de seu lucro) e revitaliza a especificidade dela, resgatando e trabalhando o mundo infantil, através do marketing 'criança-brinquedo', 'criança-lúdico', 'criança-moda'. O valor é perceptível no uso de brinquedos, que, cada vez mais, estão presentes nas prateleiras das grandes lojas, de onde a criança pode escolher bichinhos, bonecas, heróis, casinhas, videogames e outros.

Este rico universo do brinquedo, do lúdico industrializado, parece acenar para a criança (ou para seus responsáveis, que também se sentem seduzidos) com o objetivo de ser consumido e a criança o vê com o maior desejo de consumir. Contudo, as crianças desse contexto atual estão demasiadamente expostas ao consumo, desenvolvendo sentimentos de insatisfação permanente, principalmente pelas datas comerciais que de certa forma, promovem a busca pelo consumo do brinquedo, sem garantia da brincadeira.

Nesse sentido, o desejo da indústria cultural é coisificar, acorrentar e fascinar os indivíduos da moderna sociedade capitalista, para que eles se conformem com a vida cercada de injustiças em que vivem, contribuindo, assim, com a ampliação da exploração do trabalho e com a manipulação do tempo livre, além de homogeneizar o gosto da criança no âmbito da estética do brincar.

Para Horkheimer e Adorno (1985, p. 113)

[...] a mecanização atingiu um tal poderio sobre a pessoa em seu lazer e sobre a sua felicidade, ela determina tão profundamente a fabricação das mercadorias destinadas à diversão, que esta pessoa não pode mais perceber outra coisa senão as cópias que reproduzem o próprio processo de trabalho.

Assim, a indústria cultural se infiltra de tal modo na vida das pessoas (adultos e crianças) e cria todos os tipos de necessidades, mesmo onde não haja nenhuma. Sua função é propiciar uma satisfação momentânea, contudo:

[...] o consumidor não é rei, como a indústria cultural gostaria de fazer crer, ele não é sujeito dessa indústria, mas objeto. A indústria cultural abusa da consideração com relação às massas para reiterar, firmar e reforçar a mentalidades destas, que ela toma como dada a priori e imutável (ADORNO, 1986, p. 93, grifos do original). 
Há a dificuldade em acompanhar o ritmo do brinquedo ou do jogo que está na moda, tal sua agilidade, versatilidade e fugacidade. Ketzer (2003, p. 16) afirma que "o que está na mão da criança hoje, certamente será vencido por uma inovação ágil e rápida da atenta indústria cultural que, assim percebida, não se encontra imune aos tentáculos do mercado". Em outras palavras, a indústria cultural, que ajuda a construir significados simbólicos, encontra-se intimamente vinculada aos ditames impostos pela indústria do brincar, sendo necessária a discussão enquanto responsáveis pelas crianças que trouxemos ao mundo.

Silva (1991) afirma que a própria complexidade social vem expressando um tempo que se torna dolorosamente sensível às explorações cognitivas. É um tempo que favorece a educação imediatista e utilitarista, além da própria fragmentação e padronização da vida social. O convite é buscar a resistência em relação aos estigmas, padronizações e submissão ingênua diante desse novo cenário do brincar, no sentido de permitir que a criança vivencie a experiência do brincar independentemente do brinquedo, pelo viés da necessidade humana brincante, da interação e relação do sujeito no e com o mundo, seja criança ou adulto.

O brincar deve ser considerado fonte inspiradora para o aprendizado e experiência humana, resultando em características fundamentais, como: criatividade, prazer, alegria, espontaneidade, criticidade, autonomia, busca do conhecimento; todavia, atualmente, se vê outra concepção de brincar, submetida à lógica da padronização e da prontidão (a criança desenvolve uma ação diferente sobre o brinquedo, pois esse vem pronto e acabado, faz toda a ação sozinho, enquanto reflexo do avanço tecnológico), em que a única ação do pequeno se resume na sua condição de proprietário do brinquedo.

Esta condição de 'proprietário' é uma das motivações para a necessidade da troca e aquisição de novos brinquedos o que acarreta na insatisfação constante. Isso é o que provoca o desejo por outras coisas. Somente a propriedade não é suficiente para as crianças e ao perceber isso elas querem mais ou coisas diferentes.

É importante ressaltar que, se antes brincar na rua, no quintal, nas praças, era comum, atualmente já é um acontecimento raro e, quando existe, é sinônimo de violência e de perigo. A nova estrutura social contemporânea já não admite tal prática de brincar, uma vez que o aumento do número de carros nas ruas atrelado ao estresse e ausência de responsabilidade dos motoristas impedem a ação do brincar de momentos históricos anteriores. E para que as crianças não corram riscos, adultos precisam ocupá-las com computadores, videogames, televisão ou até colocam-nas em instituições educativas em período integral por conta do modo de vida contemporâneo decorrente das transformações e relações sociais associadas ao mundo do trabalho e aos valores capitalistas. 
As próprias condições de moradia verticalizadas, com espaços cada vez mais reduzidos para a brincadeira, a insegurança dos espaços públicos tem contribuído para o estabelecimento de modos diversos de distribuição do capital cultural lúdico entre as diferentes classes.

Diante disso, é necessário perceber a criança em sua individualidade, o que pode nos ajudar a responder as inquietações a partir de reflexões críticas sobre o brincar. Por sua condição de fraqueza e de promessas, a criança configura forças no seio da sociedade, seja atraindo as atenções de empresas como público consumidor, como força de trabalho, ou seja, prefigurando uma imagem de gestação. Frases como estas são ouvidas diariamente: "as crianças precisam ser educadas para competir no mercado global do futuro" ou "as crianças precisam ter acesso as formas de comunicação e tecnologias colocadas em seu tempo", entretanto, precisamos compreender que outras questões são importantes na vida e na humanidade da criança e, que estão para além da tecnologia e do consumo.

Considerando, contudo, que a lógica do capital impõe uma expropriação da autonomia e experiência do homem em benefício de seu próprio dinamismo, estaríamos assistindo a um processo de expropriação da cultura do brincar infantil? A crescente pedagogização do lúdico e a mercantilização do brincar parecem dizer que sim, haja vista que o brincar, enquanto atividade livre e expressiva da criança, é submetido à ortopedia da educabilidade e, com isso, tudo é permitido e criado, desde que vendável. Entretanto, o discurso justificador é o da valorização do brincar e do direito da criança ao brincar em oposição à proibição do trabalho infantil.

Mattelart (1986) realça uma estratégia das grandes corporações da indústria cultural do imperialismo junto à educação no "aprender rindo". Comenta o entusiasmo de um idealizador de programa de TV com a ideia de fazer a educação algo "atraente e comercializável" pela via do entretenimento. Mattelart conclui ser aquela uma evidência da estratégia de agressão cultural do imperialismo, cujo algo substantivo seria a criança: "Nesta invasão que abandona o homem médio, denominador comum da clássica cultura de massas, para setorizar seus destinatários, o público infantil é um privilegiado" (MATTELART, 1986, p. 67).

A análise de Oliveira (1986) contempla o brinquedo como mercadoria e como meio pelo qual se manifesta a cultura imperialista em países dependentes. Reconhece no brinquedo uma forma pela qual as relações materiais de produção imperialista se realizam ao lado das relações culturais. Realça, ainda, a singularidade do brinquedo em trâmites que vão além das relações de compra e venda. A atratividade, o fascínio dos bonecos, a maciez das fofoletes, enfim, a carga de valores e atitudes que vem embutida nos objetos do brincar e que participa 
do "acabamento" do consumo do brinquedo faz dele uma mercadoria singular, um signo forte da cultura.

\begin{abstract}
Junto com a diversão que lhe é inerente, o brinquedo é portador de ideias, valores, mensagens identificadoras dos pilares da cultura capitalista. Desde a racionalidade das conquistas tecnológicas, de que são exemplo os brinquedos mecanizados e os eletrônicos, até a reprodução de funções e sensações humanas, como no caso de muitas bonecas, podemos encontrar, na mensagem dos brinquedos, vários ingredientes da ideologia burguesa, que predomina tanto nos países dominantes como nos países subordinados (OLIVEIRA, 1986, p. 58).
\end{abstract}

Esses tipos de brinquedos contemporâneos têm a única finalidade de preparar a criança para o futuro estereotipado do mundo adulto, esquecendo o presente, o ser criança. A experiência de socialização da criança pelo brincar configura-se numa espécie de domesticação da infância para o gozo do capital, bem como a explosão do mundo lúdico em que as indústrias de brinquedos, sob a inspiração das teorias, sobretudo da psicologia, sugerem que o brincar não pode mais ser considerado como uma atividade fortuita, espontânea da criança, mas como algo que cabe aos adultos garantir. Por exemplo: existem bonecas que urinam: possuem um esôfago e, se lhes dão a mamadeira, molham as fraldas. Esse brinquedo tão comum prepara para a causalidade doméstica, condicionando a criança para sua futura função da maternidade.

Por meio desse cenário, a criança assume o papel do proprietário, do utente e nunca o do criador; ela não inventa o mundo, utiliza-o: os adultos preparam-lhe gestos sem aventuras, sem espanto e sem alegria. A criatividade, imaginação e simulação são substituídas ou subsumidas no brinquedo que já está pronto, que faz todo o processo imaginativo com a tecnologia e que traz o som (choro, risada, conversa, etc.). E a criança o que faz? É apenas é proprietária do brinquedo, uma vez que ela investiu financeiramente nele.

Precisamos fomentar situações cotidianas em que a criança possa manipular e construir, imaginar e criar, reaproveitar materiais que aparentemente não têm símbolo algum, mas que podem ser transformados em brinquedos e jogos em momentos de experiências infantis. A ação regida por regras começa a ser determinada pelas ideias e não pelos objetos prontos. Para tanto, é pertinente oferecer situações para as crianças criarem seus próprios brinquedos, tais como: carrinhos, caminhões, bonecas, boliches, bolas. Durante a construção desses brinquedos, ela já brinca com a imaginação, pensando no significado desse objeto.

Enfim, o mercado do brinquedo é, principalmente, um movimento de economia política na qual se realiza a mesma essência da mercadoria, como no mercado de outro 
produto qualquer. Sua qualidade específica de movimentar necessariamente o brincar, a imaginação, o lúdico confere-lhe um tom fetichizante: naturaliza-o como promotor do sonho, da alegria e de uma vida melhor.

\section{A experiência do brincar para além do brinquedo}

Trago dentro do meu coração, como num cofre que se não pode fechar de cheio, todos os lugares onde estive, todos os portos a que cheguei, todas as paisagens que vi através das janelas ou vigias, ou de tombadilhos, sonhando, e tudo isso, que é tanto, é pouco para o que eu quero (PESSOA, 1980, p. 238).

O pensamento de Fernando Pessoa (1980) nos convida a repensar a função social do brincar na contemporaneidade, sendo esta permeada pela lógica de consumo, discutida anteriormente. $\mathrm{O}$ fato que nos incomoda e nos provoca teoricamente é que, pela indústria do brincar, temos caminhado em direção à expropriação da experiência no brincar. Nossas experiências lúdicas vêm sendo solapadas no imenso turbilhão de seduções e de fetiches, em que somos provocados na arena do capital e do consumo.

Entretanto, o brinquedo e o brincar são invenções tão antigas quanto o homem. Não se condicionam, necessariamente, a objetos de brincar, nem a uma forma determinada de sua produção, a industrial, que hoje se impõe como hegemônica na relação criança-brinquedo. Tão pouco se restringe à criança.

A criança entra no cenário do mercado de brinquedos com a condição essencial de ser, em última instância, detentora de poder de compra, uma determinação que, grosso modo, resgata a condição da criança como membro de uma família e de uma classe social para fazer valer a sua relação com o brinquedo. Por esta questão, ficariam de fora as crianças que, não tendo poder de compra, não alimentam o movimento do mercado dos brinquedos.

Oliveira (1986) questiona: as crianças que não têm poder de compra, mas que são crianças, têm acesso ao brinquedo e afirmam a identidade da criança como sujeito que brinca? Esta é uma questão que, conforme afirma o autor, é mostrada na prática pelos brinquedos que as crianças inventam a partir de objetos não feitos brinquedos. No que toca a prática da construção de brinquedos, vemos seu esvaziamento em troca da compra. "É incomum as crianças se ocuparem (entre nós) em seu lazer de transformar, elas próprias, os elementos cedidos pela natureza para construir brinquedos" (OLIVEIRA, 1986, p. 35).

Devido à atual confluência da sofisticada tecnologia do brincar e a glorificação do consumismo, está ficando cada vez mais difícil a satisfação humana, através da emoção, do 
prazer, da espontaneidade, da interação, bem como a manifestação criativa e inventiva de crianças durante a vivência do brincar. Extingue-se a construção, pela criança, de seus próprios brinquedos e de brincar com diferentes alternativas: cones, linhas, caixas, brinquedos de montar e desmontar, brinquedos confeccionados com materiais alternativos. O tempo e o espaço para suas próprias ideias e suas próprias imagens, para interpretação sem pressa com texto e ilustrações diminui a cada sucesso de filmes e programas infantis - inevitavelmente acompanhados por uma série de brinquedos, livros, vídeos e roupas relacionadas.

Walter Benjamin (1987) ${ }^{5}$ já chamara atenção para o fato de que, na história cultural do brincar, o brinquedo sempre foi um objeto lançado do mundo adulto ao mundo infantil. Brinquedos antigos, como a bola e a pipa, são derivados de cultos religiosos que, uma vez dessacralizados, permitiram o desenvolvimento das fantasias infantis. Quanto mais simples o artefato lúdico mais permite e aguça o desenvolvimento do imaginário infantil. Não há qualquer atividade, mas a atividade criadora, a que age igualmente impulsionada pelas experiências emocionais, intelectuais e sensoriais tanto da criança quanto do adulto.

Assim, as crianças pequenas apresentam a espontaneidade em suas brincadeiras. Elas têm capacidade para sentir e pensar o que é realmente delas; essa espontaneidade se revela no que dizem e pensam, nos sentimentos que expressam em seus rostos. Fromm (1968, p. 206) afirma que a maioria dos seres humanos pode observar momentos de própria espontaneidade, que são, ao mesmo tempo, de legítima felicidade. Em função disso, é preciso trabalhar numa perspectiva de humanização, valorizando a experiência, as emoções, os sentimentos, os desejos, a própria espontaneidade infantil, as relações afetivas através de experiências com o brincar.

O canteiro de obras, citado por Benjamin (2002), incita-nos a refletir acerca do rico universo de possibilidades lúdicas para as crianças, precisamente para o desenvolvimento da atenção, pensamento e ação. Segundo ele, as crianças são inclinadas a buscar todo local de trabalho onde a atuação sobre as coisas se processa de maneira visível. Desse modo, Benjamin (2002) evoca lembranças de sua infância, e estas nos levam à compreensão do sujeito desvinculado do eu; são narrativas que nos possibilitam pensar sobre a nossa prática histórica, isto é, como contamos a nossa história e como agimos nela. Elas descortinam uma vista privilegiada do universo da criança.

${ }^{5}$ Walter Benjamin (1892 -1940) produziu uma obra rica em dimensões e diversidade de temas: de questões pedagógicas, ao movimento estudantil, a jogos e brinquedos, também cartilhas e livros infantis. Desse modo, a possibilidade de familiarizar-se com as contribuições benjaminianas acerca do jogo e do brinquedo possibilitanos melhor aprofundar esse tópico de discussão (BENJAMIN, 1984). 
Canteiro de obras: as crianças [...] sentem-se irresistivelmente atraídas pelo resíduo que surge na construção, no trabalho de jardinagem ou doméstico, na costura ou na marcenaria. Em produtos residuais reconhecem o rosto que o mundo das coisas volta exatamente para elas, e para elas unicamente. Neles, elas menos imitam as obras dos adultos do que põem materiais de espécie muito diferente, através daquilo que com eles aprontam no brinquedo, em uma nova, brusca relação entre si. Com isso as crianças formam para si seu mundo de coisas, um pequeno no grande, elas mesmas. Seria preciso ter em mira as normas desse pequeno mundo de coisas, se se quer criar deliberadamente para as crianças e não se prefere deixar a atividade própria, com tudo aquilo que é nela requisito e instrumento, encontrar por si só o caminho que conduz a elas (BENJAMIN, 1987, p. 18, 19).

Benjamin (2002), ao referir-se aos velhos brinquedos, especificamente à exposição de brinquedos no Märkische Museum, de Berlim, evoca a importância do brincar enquanto libertação e exalta que os mais belos brinquedos conhecidos por acervos de museus e de colecionadores são originários da Alemanha - "um presente alemão à Europa" (BENJAMIN, 2002, p. 67).

Afirma o autor que a criança, mesmo rodeada por um mundo de gigantes, cria para si, brincando, o pequeno mundo próprio:

[...] mas o adulto, que se vê acossado por uma realidade ameaçadora, sem perspectiva de solução, liberta-se dos horrores do real mediante a sua reprodução miniaturizada. A banalização de uma existência insuportável contribuiu consideravelmente para o crescente interesse que jogos e livros infantis passaram a despertar após final da guerra. Nem todos os novos estímulos direcionados então à indústria de brinquedos foram-lhe úteis. A melindrosa silhueta das figuras laqueadas que, entre tantos produtos antigos, representam a modernidade, não constitui propriamente nenhuma vantagem para esta; tais figuras caracterizam antes aquilo que o adulto gosta de conceber como brinquedo do que as exigências da criança em relação ao brinquedo. São coisas meramente curiosas. Aqui são úteis apenas para fins de comparação, num quarto de criança não servem para nada (BENJAMIN, 2002, p. 85-86).

Acrescenta que há algo que não pode ser esquecido:

[...] jamais são os adultos que executam a correção mais eficaz dos brinquedos, sejam eles pedagogos, fabricantes ou literatos, mas as crianças mesmas, no próprio ato do brincar. Uma vez extraviada, quebrada e consertada, mesmo a boneca mais principesca transforma-se numa eficiente camarada proletária na comuna lúdica das crianças (BENJAMIN, 2002, p. 87). 
Benjamin (2002), desde o início do século XX, criticava a modernidade e o risco de se perder a capacidade de narrar, porque a experiência se empobrece e se torna vivência: na vivência, reagimos aos choques do cotidiano, e a ação se esgota no momento de sua realização, por isso é finita; na experiência, o que é vivido é pensado, narrado, a ação é contada a outro, partilhada, tornando-se finita. Eis o seu culto aos velhos brinquedos, pois acreditava que estes guardavam uma qualidade distinta dos produzidos com o avanço da sociedade industrial (modernidade). Naqueles brinquedos, para Benjamin (2002), havia uma relação social e familiar que envolvia pais e filhos no fazer o brinquedo. A simplicidade, a técnica de produzi-lo, as dimensões reduzidas e a discrição que vê marcarem os "velhos" e "belos" brinquedos dava ao objeto o seu encantamento. O brinquedo da grande indústria, ao contrário, subtraía a relação de pais e filhos de sua feitura, esvaziava a mediação do brinquedo (peça de produção) da relação pedagógica criada em sua feitura.

Uma emancipação do brinquedo começa a impor-se: quanto mais a industrialização avança, mas decididamente o brinquedo subtrai-se ao controle da família, tornando-se cada vez mais estranho não só às crianças, mas também aos pais (BENJAMIN, 1987, p. 68).

Considerada a crítica de Benjamin $(1987,2002)$ à produção industrial do brinquedo e sua exaltação ao brinquedo artesanal e da pequena indústria como portadores de autenticidade, frise-se o seu entendimento sobre a essência do brincar, que não se limita ao objeto, mas se acresce de experiências que são vivenciadas em momentos de brincar. Ele indica a essência do brincar como "um fazer de novo" e não como um "fazer como se". ${ }^{6} \mathrm{~A}$ repetição, o "saborear de novo sempre como renovada intensidade os triunfos e vitórias", que ele entendia estar na essência do brincar, parece assumir no seu pensamento o sentido de uma experiência sempre renovada. Não se identifica, portanto, a uma mera repetição do velho, mas à busca de um novo, que se escondeu pelas fímbrias do velho.

Tudo correria com perfeição, se pudesse fazer duas vezes as coisas: a criança age segundo este pequeno verso de Goethe. Para ela, porém não basta duas vezes, mas sim sempre de novo, centenas e milhares de vezes. Não se trata

${ }^{6}$ A cada momento do brincar, constitui-se um pensamento e um fazer de novo, o que é infinita a experiência e a essência do brincar. 
apenas de um caminho para tornar-se senhor de terríveis experiências primordiais, mediante o embotamento, os juramentos maliciosos ou paródia, mas também de saborear, sempre com renovada intensidade, os triunfos e vitórias (BENJAMIN, 1987, p. 75).

Desse modo, na brincadeira, a criança transforma os objetos em outros. Seu olhar, igual à lente de uma câmera, penetra os objetos e descobre neles a vida das coisas. A criança constrói seu universo particular, dando outra significação ao cotidiano. Assim, ele nos permite penetrar na magia da infância e descobrir com ela e por meio dela o mistério que emana do mundo dos objetos, pois são eles que alimentam a imaginação, dando conteúdo e forma aos segredos que revelam.

\section{Considerações finais}

Diante das discussões apresentadas, podemos inferir à luz de Benjamin (1987) que as crianças não brincam apenas, mas transformam-se. Não se limitam a encenar que são professores, médicos, comerciantes, mamãe ou papai, mas transformam-se em trens, aviões, cavalos, gatos, ou seja, elas imitam o real, sendo aquilo que sua imaginação realmente desejar: pessoa, animal ou coisa.

Para tanto, é necessário um olhar de ressignificação do brincar para além do objeto brinquedo tecnológico, no sentido de pensar no processo criativo, inventivo, interativo, lúdico e humanizador que essa experiência brincante pode potencializar na criança desde a mais tenra idade. Ainda, a partir de pressupostos benjaminianos, vê-se na criança a dimensão cinematográfica que seu olhar revela e nos mostra, com grande sensibilidade e beleza, uma vez que os objetos se tornam, para ela, um reino de enigmas que podem ser decifrados em diversas direções.

Em contraposição ao mundo da mercadoria e do adulto seduzido pelos fetiches do consumo, a criança precisa vivenciar experiências lúdicas promotoras da criatividade, criação e reelaboração do brincar e da brincadeira enquanto necessidade humana e de interação criança - mundo; criança - outro. Assim, "A criança quer puxar alguma coisa e torna-se cavalo, quer brincar com areia e torna-se padeiro, quer esconder-se e torna-se bandido ou guarda [...]. (BENJAMIN, 2002, p. 93). Desse modo, o brincar deve ser permeado por situações diversas que vão além do objeto, da mercadoria. Dado esse fato, ousamos, ao invés de contribuir para a expropriação, contribuir para a apropriação verdadeira e criativa do 
brincar, por meio da imaginação, fantasia e construção criativa e simbólica da experiência lúdica infantil.

\section{REFERÊNCIAS}

ADORNO, T. W. Indústria Cultural. In: COHN, G. Sociologia. São Paulo: Ática, 1986.

BELLONI, M. L. O que é sociologia da infância. Campinas: Autores Associados, 2009. (Acadêmico de bolso).

BENJAMIN, W. Magia e Técnica, arte e política: ensaios sobre literatura e história da cultura. Tradução de Sergio Paulo Rouanet. 7. ed. São Paulo: Brasiliense, 1984. (Obras escolhidas, v. 1).

BENJAMIN, W. Reflexões sobre o brinquedo, a criança e a educação. São Paulo: Editora 34, 2002.

BENJAMIN, W. Rua de mão única. v. 2. São Paulo: Brasiliense, 1987. (Obras escolhidas).

BROUGÉRE, G. Brinquedo e Cultura. São Paulo: Cortez, 1995.

FROMM, E. O medo da liberdade. Rio de Janeiro: Zahar, 1968.

HORKHEIMER, M.; ADORNO, T. W. A Dialética do Esclarecimento: Fragmentos filosóficos. Rio de Janeiro: Jorge Zahar, 1985.

KEHL, M. R. Imaginar e Pensar. In: NOVAES, A. (Org.). Rede imaginária: televisão e democracia. São Paulo: Companhia das Letras, 1991.

KETZER, S. M. A criança, a produção cultural e a escola. In: MAGALHÃES, C. et al. A criança e a produção cultural - Do brinquedo à literatura. Porto Alegre: Mercado Aberto, 2003. p. 11-27.

LINN, S. Crianças do consumo: a infância roubada. Tradução Cristina Tognelli. São Paulo: Instituto Alana, 2006.

MARCUSE, H. Eros e civilização: uma interpretação filosófica do pensamento de Freud. Rio de Janeiro: Zahar, 1975.

MARX, K. O Capital. Crítica da Economia Política. Livro 1, v. 1, 10. ed. São Paulo: Difel, 1985.

MATTElaRT, A.; MATTELART, M. Penser les médias. Cap. 4-8, Tradução de Vera L. Westin e Lúcia Lamounier (mimeogr.). Paris: La Découverte, 1996. (Original: 1986).

OLIVEIRA, P. S. Brinquedo e indústria cultural. Petrópolis: Vozes, 1986. 
PESSOA, F. (Álvaro de Campos). O Eu profundo e seus outros eus: seleção poética. Rio de Janeiro: Nova Fronteira, 1980.

SILVA, T. T. da. O que produz e o que reproduz em educação. Ensaios de Sociologia da Educação. Porto Alegre: Artes Médicas, 1991.

\section{Como referenciar este artigo}

OLIVEIRA, Marta Regina Furlan de, SOUZA, Ravelli Henrique de, ARAÚJO, Karina de Toledo. Brinquedo sem brincadeira: reflexões sobre a indústria do brincar na infância contemporânea. Título. Doxa: Rev. Bras. Psico. e Educ., Araraquara, v. 21, n. 1, p. 28-43, jan./jun. 2019. e-ISSN: 2594-8385. DOI: https://doi.org/10.30715/doxa.v21i1.13060

Submetido em: $10 / 12 / 2018$

Aprovado em: 30/01/2019

Publicado em: 01/02/2019 